\title{
Equity and efficiency considerations in setting standards for flood protection
}

\author{
H. van der Most \\ Deltares, Department of Climate Adaptation and Risk Management, \\ The Netherlands
}

\begin{abstract}
The current standards for flood protection in The Netherlands are some 50 years old. The growth, in both the number of people and the assets to be protected, calls for a revision of these standards. In setting new standards, trade-offs have to be made (again) between goals of economic efficiency and societal equity. The current standards show only limited regional differentiation in the level of protection against floods. Preliminary cost benefit analyses, as well as studies on casualty risk, indicate that a larger differentiation could be justified on economic grounds. The question is, however, whether this will be acceptable from a societal point of view or not.

To this end the paper will discuss the findings of surveys of public perception of flood risk, including perceptions of whether it is right or acceptable to differentiate in the level of protection of different parts of the country. The paper will also present and discuss the outcomes of round table discussions with decision-makers, representatives of NGOs and the business community. The surveys of public perception showed more support for differentiation than decision-makers were inclined to expect during the round table discussions. The paper will conclude with suggestions on how to deal with the tension between equity and efficiency in a constructive manner. This includes broadening the base of the current standards with an explicit consideration of casualty risk.
\end{abstract}

Keywords: flood risk management, standards, flood protection, economic efficiency, social equity, risk perception, The Netherlands. 


\section{Current flood protection standards}

Due to its low elevation, The Netherlands is vulnerable to flooding from the sea and the large rivers that pass through the country, such as the river Rhine (see Figure 1).

Throughout the ages, dikes have been built to control the risk of flooding, often in response to a flood disaster. The current standards for flood protection were proposed by the Delta Committee following the major flood of 1953, which struck the south-western delta of The Netherlands. The standards were derived based on an economic optimization of investment costs and the benefits of damage reduction. The risk of casualties was not explicitly included in setting standards as there was at that time insufficient knowledge to assess the number of casualties due to flooding.

The standards were defined as the frequency of exceedance of the design water level for the various dike ring areas. Four different levels of standards were defined, taking into account the nature of the threat as well as the values to be protected. The safety standards range from $1 / 1,250$ per year for the river dike rings in the east of the country to $1 / 10,000$ per year for the coastal dike rings of North and South Holland. Figure 2 shows the safety standards for all 53 dike rings of The Netherlands.

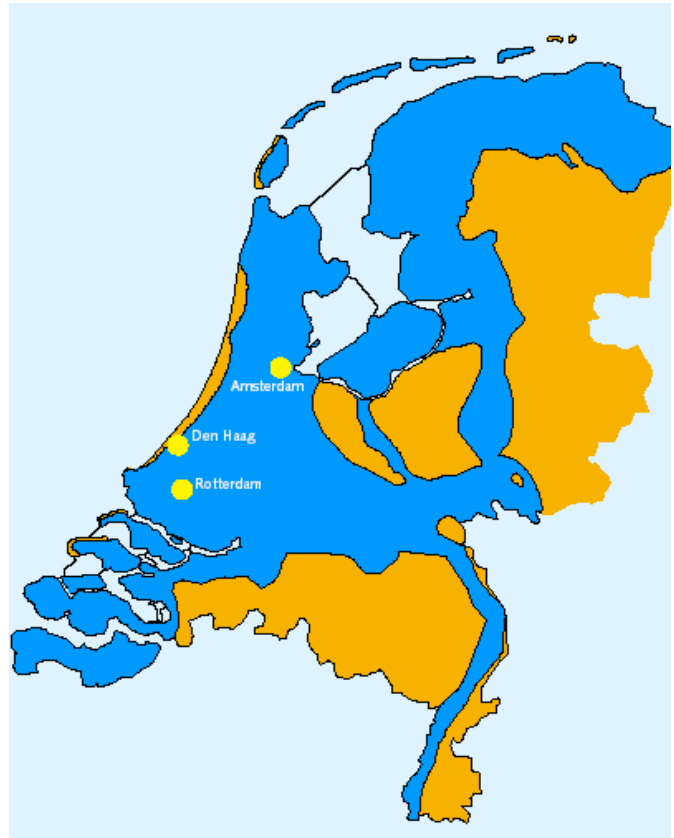

Figure 1: Vulnerability to flooding. 


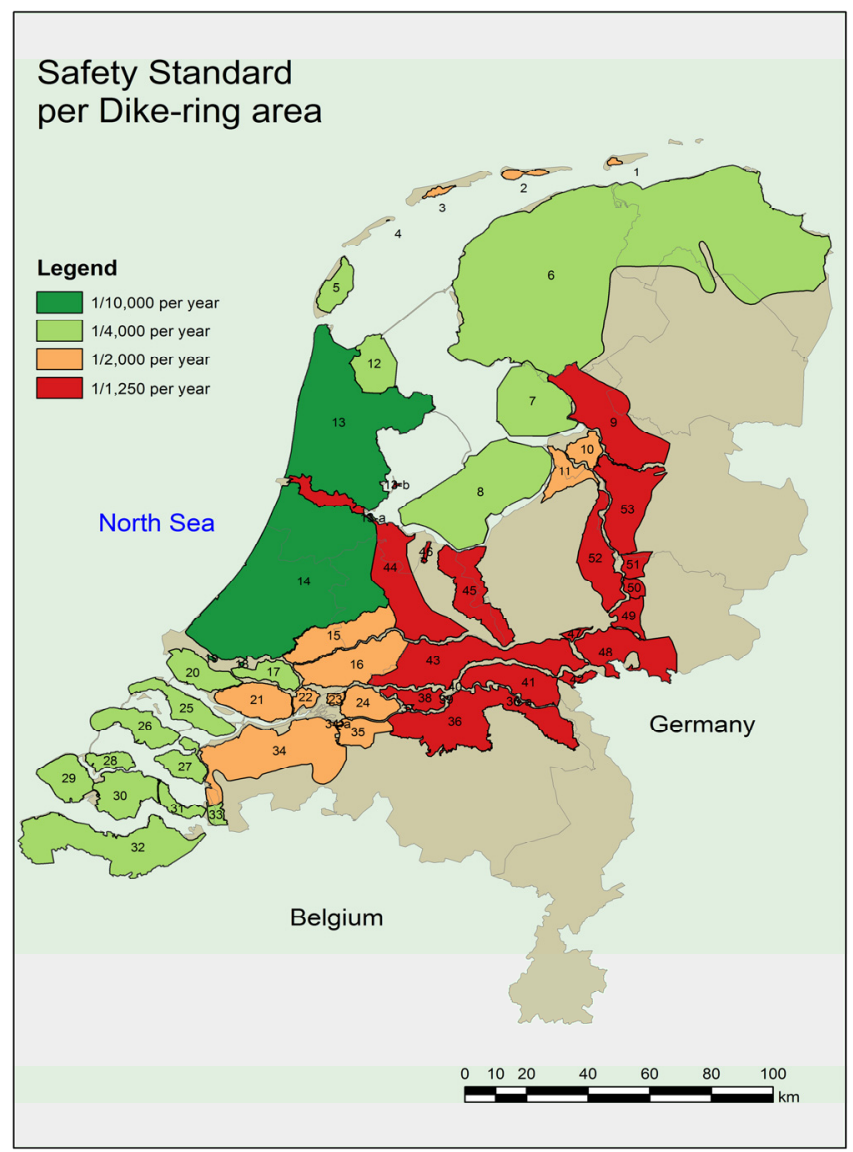

Figure 2: $\quad$ Safety standards by dike ring area.

The current standards show a number of drawbacks. (1) The differentiation in safety standards is small in view of economic efficiency of investments. (2) The standards are only based on economic costs and benefits; the risk of casualties was not considered. (3) The standards focus on the water defences surrounding the dike ring area and do not pay attention to the distribution of the flood risk within the dike ring area. A few years ago the policy project 'Water Safety $21^{\text {st }}$ Century' was initiated. The policy project will produce a system of new safely levels to be proposed to Parliament in 2011. This policy project may open opportunities to avoid or at least reconsider some of the drawbacks of the current system of standards, e.g. better dealing with the issue of differentiation. 


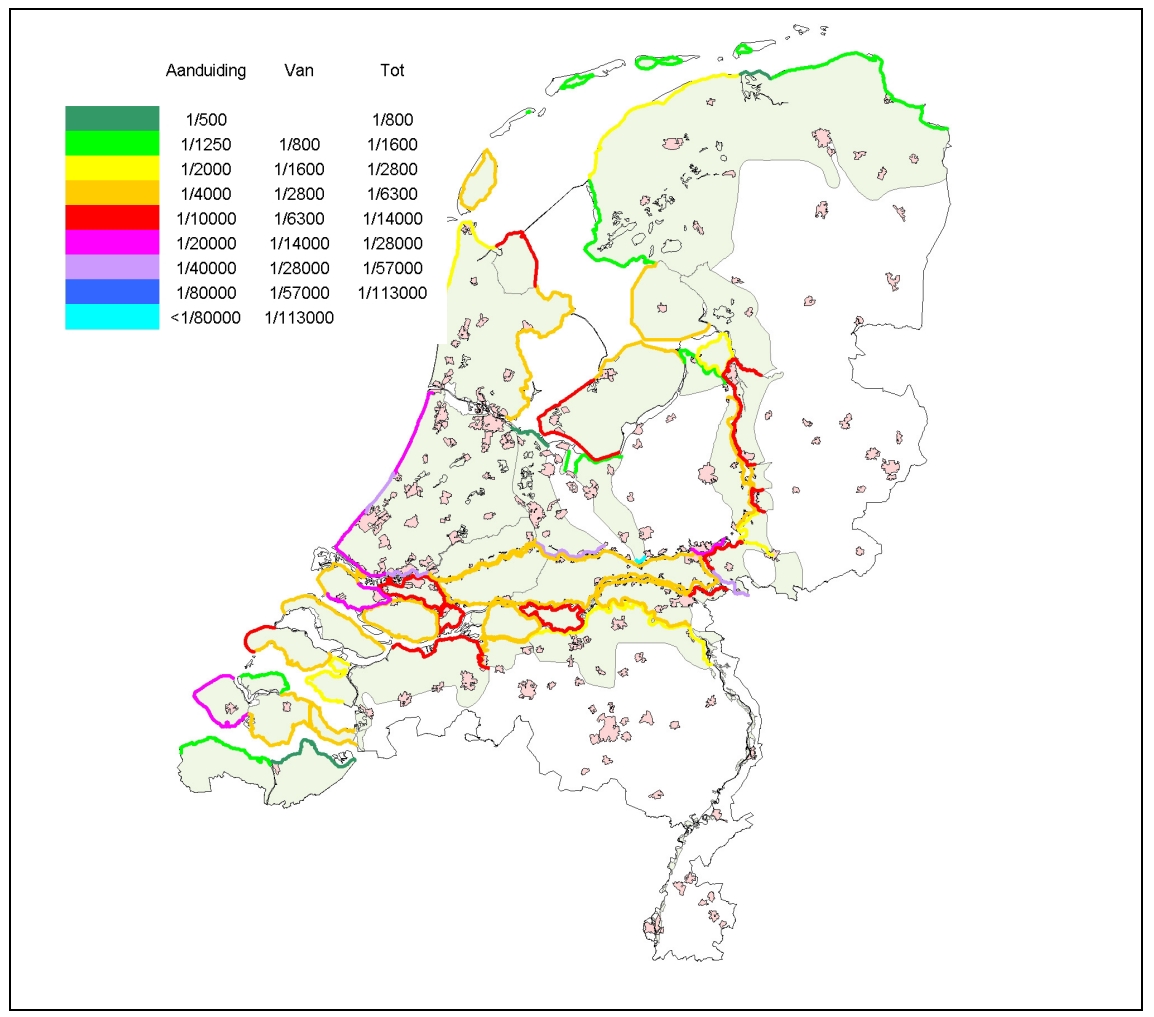

Figure 3: Economically optimal flood probabilities.

\section{Road to new standards for flood protection}

\subsection{Cost benefit analysis of flood protection levels}

The current standards were established some 50 years ago and are in urgent need of actualization. Within the framework of the policy project 'Water Safety $21^{\text {st }}$ Century' a provisional cost benefit analysis was carried out at the end of 2008 presenting the economically optimal flood probabilities for each dike ring [1]. The results are shown in Figure 3.

Comparison of the economically optimal flood probabilities with the current standards provides insight to what extent the current standards need revision. In most dike rings the standards should be strengthened with a factor 2-4 (compare the figures 2 and 3). However, there are also about ten dike rings where strengthening of the current standards cannot be justified on economic grounds. In only a few dike rings the standard should be strengthened with more than a factor 5. The general 'expectation' that current standards would be (much) too low in most dike rings is not supported by the cost benefit analysis. Anyway, from an economic perspective, strengthening of the current standards should be 
considerably less than the factor 10 that was recommended by the second Delta Committee in its report of September 2008 [2].

\subsection{Broadening the base for setting standards}

The current standards are based on optimization of economic costs and benefits. Casualty risks as such are no part of the current standards, although these risks are generally considered the most important impact of flooding. This shortcoming of the current standards has been recognized and the Draft Policy Note on Water Safety [3] announces that the base for setting standards will be broadened: 'The height of new standards will be the result of a political evaluation per dike ring area. Criteria for this evaluation will at least include the economic efficiency of investments in water safety (based on a societal cost benefit analysis) and the potential number of casualties in case of a flood'.

Explicit consideration of casualty risks is new within water safety policy. Two dimensions of casualty risk are being considered: basic safety and societal disruption. Basic safety is described by the individual risk of becoming victim of a flood, whereas societal disruption is represented by the probability of disasters with a large number of victims, also called the 'group risk' [4].

\subsection{Dealing with differentiation in the level of protection}

The outcomes of the cost benefit analysis show a wider variation in the economic optimal level of protection than the current standards. The economic optimum flood probability of dike rings ranges from larger than $1 / 1,000$ per year to smaller than 1/100,000 per year: a difference of at least a factor 100 . Provisional studies into casualty risk show a large variation too. There is also about a factor 100 between the largest and the smallest contribution of dike rings to the national 'group risk'. A band width which is comparable with the one found in the cost benefit analysis.

So, both cost benefit analysis and studies into casualty risks suggest that there is room for a stronger differentiation in protection level as compared to the current standards, which only show a factor 8 between the largest (1/1,250 per year) and smallest probability (1/10,000 per year). Considerations of social equity may, however, pose limits to the degree of (regional) differentiation. An argument often used in this context is that it is hard to explain to people in a particular dike ring that their protection level is different (i.e. less) from a neighbouring dike ring. At first glance this seems a strong argument. The argument loses weight, however, if one examines the map with the current standards more carefully (see figure 2). It then shows that already with the current standards most dike rings border at least one dike ring with a different protection level; with the exception of some river dike rings in the eastern part of the country and some dike rings in the south-western delta.

Nevertheless, perceptions and opinions on what are reasonable differences will determine the acceptability of differentiation in the level of protection. Such perceptions have been investigated in surveys of public perception of flood risk in a couple of dike rings. The issue of differentiation was also the subject of 
round table discussions with decision-makers, representatives of NGO's and the business community. The next section will present and discuss the findings of the surveys and round table discussions.

\section{Perceptions of differentiation in protection level}

\subsection{Perceptions on differentiation from round table discussions}

Differences in the current protection levels of the dike rings were discussed in round table discussions with local and regional decision-makers and/or administrators (provinces, water boards, municipalities) as well as representatives of NGO's and the business community. Round table discussions were organized for about 15 out of the 53 dike rings. In most round table discussions a comparison was made with the standard for dike ring 14. This is the dike ring Central Holland, which comprises the economic heart of The Netherlands and includes major cities such as Amsterdam, Rotterdam and The Hague. This is also the dike ring with the highest standard for flood protection.

In a few, more rural dike rings, regional sentiments played a major role in the perception of the differences in standards. The discussions in these dike rings showed quite some mistrust to the national government (located in The Hague in the dike ring Central Holland). There is in fact a plea to decide regionally on the level of protection. The perception is that the national government wants to differentiate and that the region has nothing to gain in such process.

The comparison with the dike ring Central Holland was also at stake in some other dike rings which are located close to dike ring 14. For these dike rings (e.g. the dike rings 17 and 22) there was a plea to strengthen the standard to the same level as in dike ring 14. In the round table discussion the similarities with dike ring 14 were emphasized: a high population density, a lot of capital invested and a concentration of vital infrastructure to support their case.

The round table discussions showed a rather wide array of perceptions on differentiation: there were strong adversaries of differentiation in some dike rings, whereas in other dike rings differentiation was viewed as a logical consequence of differences in the values to be protected. In most round table discussions there was at least some reservation with respect to differentiation. In those dike rings where the need for differentiation was recognized, the acceptance of differentiation was coupled to the presence of a certain basic safety.

\subsection{Public perception of regional differences in flood risk}

The perception of households of flood risks has been investigated in the PROmO-project. This project included a survey under some 1500 respondents in three different dike rings [5]. The perceptions of households of both probabilities and consequences of floods have been compared with expert judgements. This comparison showed that people have a reasonable picture of differences in flood risk between dike rings. Earlier research has shown that people have difficulty in 
comprehending small probabilities such as $1 / 1,000$ or $1 / 10,000$ per year, but their view of regional differences in flood risk fits well with expert judgement. The same understanding of regional differences in flood protection standards was found in the round table discussions.

The PROmO-project also looked more explicitly into the issue of differentiation of protection levels, the tension between equity and efficiency. Respondents in the dike rings were invited to express their views on a number of questions to clarify their attitude with respect to differentiation [6]. The questions were concerned with the acceptability of differences in the level of protection; for some example questions see box 1.

The first general question relates to the basic attitude of the respondents, whether they favour efficiency or equity. Some $56 \%$ of the respondents indicated that the protection level may differ by area. Another $10 \%$ of the respondents find differences acceptable, provided that certain conditions are met. For $31 \%$ of the respondents the level of protection should be equal in all dike rings. So, the number of respondents which favour some degree of differentiation is about twice the number of respondents which favour equity.

An important issue is whether this basic attitude is robust or not? This issue has been examined by raising two additional questions with more specific proposals for flood protection standards. Box 1 contains one example of these more specific questions.

These specific questions comprised policy proposals with different standards for areas A and B based on differences in the expected number of victims as well as the probability of becoming a victim of flooding. The question then was whether differences in consequences should imply differences in flood

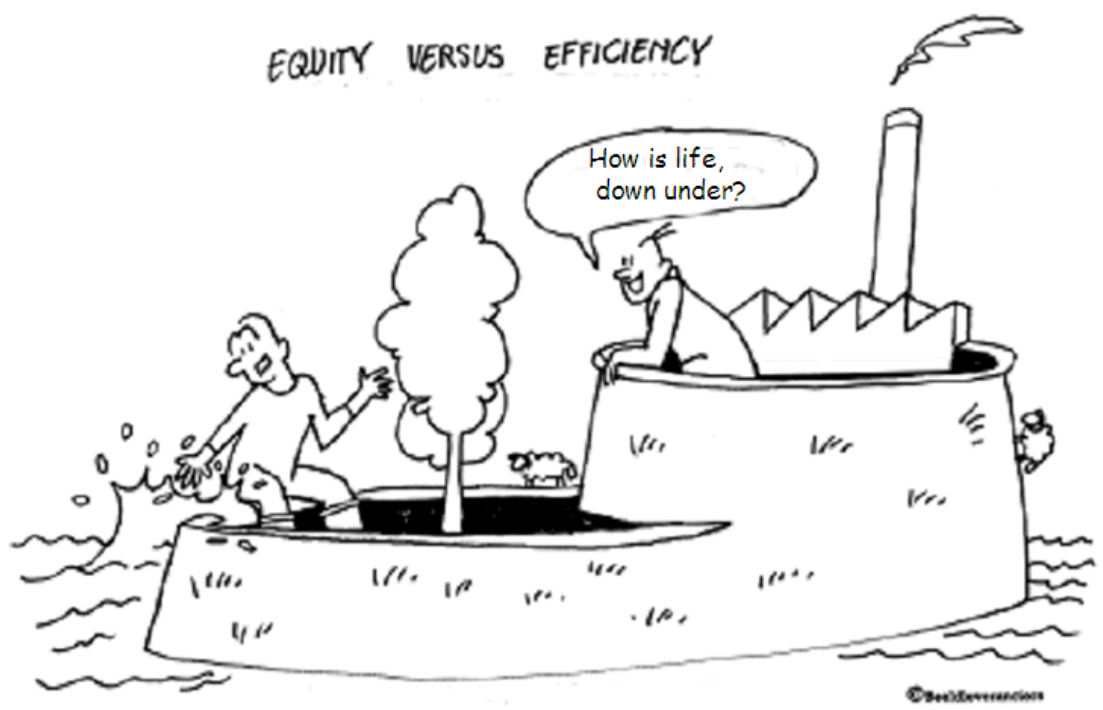

Figure 4. 


\section{Example questions on issue of 'equity vs. efficiency'}

\section{General question 1}

Suppose that there is a policy proposal which includes different safety levels for different areas. The proposal takes into account the number of inhabitants as well as the expected damage in the areas in case of a flood. In each proposal the safety level remains at least the same as in the present situation.

Would you support such policy of the government?

- $\quad$ Yes, safety levels may differ by area;

- $\quad$ Maybe, safety levels may differ by area, but only under certain conditions, such as

- $\quad$ No, safety levels should be equal everywhere.

\section{Specific question 2}

Another policy proposal implies that different areas (A and B) will have different safety levels, depending on the expected number of deaths in case of flooding of the area.

\begin{tabular}{|l|c|c|}
\hline & AREA A & AREA B \\
\hline $\begin{array}{l}\text { Flood probability } \\
\text { (in the next 50 years) }\end{array}$ & $\mathbf{5 \%}$ & $\mathbf{2 . 5 \%}$ \\
\hline $\begin{array}{l}\text { Expected number of victims in } \\
\text { case of a flood }\end{array}$ & $\mathbf{1 0 0}$ & $\mathbf{1 , 0 0 0}$ \\
\hline Number of inhabitants in area & $\mathbf{1 0 0 , 0 0 0}$ & $\mathbf{1 , 0 0 0 , 0 0 0}$ \\
\hline
\end{tabular}

What is your opinion of the proposal above for the areas A and B?

- The proposal is acceptable.

- The proposal is as it should be.

- The proposal is unacceptable, the flood probability should be equal in both areas.

Figure 5. 
probabilities. Comparison of the response to the general question, with the responses to the two specific questions, reveals whether respondents are distinct supporters of differentiation or equity. If respondents favoured equity for all questions, they were labelled as 'distinct supporters of equity'. A similar reasoning applied to 'distinct supporters of differentiation'. With the specific questions, the respondents were more or less 'seduced' to adapt their view. A modest number of respondents used that opportunity and indicated that after all they favoured the other choice. These respondents were labelled as 'equity on second thoughts' resp. 'differentiation on second thoughts'. About $75 \%$ of the respondents could be categorized in one of these four different viewpoints; the other $25 \%$ of respondent evaluated the questions 2 and 3 differently. All by all the number of distinct supporters of differentiation is about twice the number of distinct supporters of equity (see also Table 1).

The PROmO-project also looked into the different factors which may explain a particular viewpoint. Respondents with a lower education are more often 'distinct supporters of equity' than respondents with higher or academic education. Most 'distinct supporters of equity' are found in the rural dike rings of Zeeland (some 26\%), whereas the more 'urban' dike ring of Central Holland has the smallest percentage of supporters of equity (only 11\%). The age of respondents plays a role too: 'young people' (age 18-34 years) favour equity less than people in the age of 35-64. Analysis shows further that experience with (near) floods and evacuation has no significant influence on viewpoints with respect to differentiation or equity.

Research shows that there is quite some variance in the perceptions of households with respect to the issue of differentiation. Nevertheless, the number of proponents of differentiation constitutes a majority. It appears that there is under households more understanding and support for differentiation than local and regional administrators were inclined to assume in the round table discussions.

\section{Using perceptions in the set-up of new standards}

\subsection{Triggers for adaptation of the current standards}

The current standards for flood protection show a limited degree of differentiation. Provisional cost benefit analysis indicates that a larger degree of

Table 1: $\quad$ Perceptions of households on differentiation.

\begin{tabular}{|c|c|}
\hline $\begin{array}{c}\text { Perceptions on differentiation vs. equity } \\
\text { Source :[6] }\end{array}$ & Percentage of respondents \\
\hline Distinct supporter of equity & 18.1 \\
Equity on second thoughts & 10.3 \\
\hline Distinct supporter of differentiation & 38.1 \\
Differentiation on second thoughts & 7.0 \\
\hline
\end{tabular}


differentiation is attractive from an economic perspective. Studies of casualty risks show that a larger differentiation could be attractive from that view-point as well. Equity considerations, however, may limit the degree of differentiation.

Apart from the height, also the base of the standard is subject of debate. The base of the standards will be broadened with an explicit consideration of casualty risks in deciding what should be the future protection level of dike rings. This development fits well with the general perception that casualties are the most important impact of flooding.

\subsection{Bridging the tension between efficiency and equity}

In setting standards for flood protection there is a tension between economic efficiency and social equity. This tension was an issue of concern in most round table discussions. The reports of the round table discussions show varying perceptions on differentiation: from outspoken adversaries to people that accept differentiation as a logical consequence of differences in values to be protected. In quite a few round table discussions, the participants indicated that the acceptance of differentiation will be related to guarantees of a tolerable casualty risk.

\subsection{Dealing with differentiation in the set-up of new standards}

The new base for setting standards comprises three criteria: economic efficiency of investments, offering basic safety and preventing social disruption. Each criterion can be elaborated into required levels of protection for the dike rings in The Netherlands. In setting new standards for flood protection, these requirements should be somehow combined. One option is to take for each dike ring the perspective with poses the highest requirements. This is in fact the approach which is currently being considered. Such approach has, however, the disadvantage that the tension between efficiency and equity is 'hidden' in one standard. Other options may be considered, which better reckon with the variance in perceptions on differentiation.

The explicit consideration of casualty risk is a new element in water safety policy. Such new element should preferably be made visible in the new system of standards, the more so because casualty risk are generally considered the most important impact of flooding. A separate standard for basic safety would emphasize the new attention to casualty risk.

Such two track approach offers a number of advantages. The two types of standards may give direction to different 'governing perspectives'. The standard for the flooding probability of the dike ring is above all a prevention standard to be applied in the evaluation and design of water defences. The standard for basic safety may govern the implementation of a more sustainable, flood-proof spatial planning as well as the implementation of emergency management. The two track approach may reduce the institutional complexity of an integrated water safety policy.

The standard of basic safety could also be used to communicate that the government guarantees a minimum level of safety to all inhabitants of The 
Netherlands (like a basic health care). Such guaranteed level of safety may contribute to support for a stronger degree of differentiation in flood protection standards, as became apparent from the round table discussions. Acceptance of a stronger degree of differentiation in its turn contributes to the goal of economic efficiency of investments in water safety.

\section{References}

[1] Rijkswaterstaat, Waterdienst, 'Waterveiligheid $21^{\mathrm{e}}$ eeuw; Kengetallen Kosten-batenanalyse', Kind, J.,rapportnummer: WD2008.044, 1 September 2008 (in Dutch).

[2] Deltacommissie (2008), Working together with water, A living land builds for its future, Findings of the Deltacommissie 2008, September 2008, The Hague, The Netherlands.

[3] Ministry of Public Works, Transport and Water Management (2008), Draft Policy Note on Water Safety, 22 December 2008 (in Dutch)

[4] De Bruijn, K., J. Beckers and H. van der Most (2010), Casualty risks in the discussion on new flood protection standards in the Netherlands, FRIAR 2010 Conference, May 2010, Milano, Italy.

[5] Terpstra, T. (2009). Flood preparedness Thoughts, Feelings and Intentions of the Dutch Public, PhD Thesis, Twente University, December 2009.

[6] Bockarjova, M., A. van der Veen, P. Geurts (2009). Reporting on flood risk perception in the Netherlands II: An issue of equity or differentiation? Working document of PROmO-project, ITC, June 2009. 